\title{
Possible mechanism of hepatoprotective activity of Azadirachta indica leaf extract against paracetamol- induced hepatic damage in rats: Part III
}

Paracetamol (acetaminophen) is a widely used analgesicantipyretic agent which is metabolised by the liver. Over dosing of paracetamol to rats is reported to decrease their sensitivity to its hepatotoxic effects, which are associated with oxidative stress. ${ }^{[1]}$ So the studies on antioxidant enzymes, (Glutathione peroxidase (GPx), glutathione-S-transferase (GST), superoxide dismutase (SOD) and catalase (CAT) have been found to be of great importance in the assessment of liver damage. Azadirachta indica (Meliaceae; Neem) is an indigenous plant possessing several medicinal properties. Through our previous study we have reported the hepatoprotective activity of Azadirachta indica against paracetamol induced hepatic damage in rats. ${ }^{[2]}$ In the present study the effects of $A$. indica leaf extract on antioxidant enzymes have been investigated to elucidate the possible mechanism of its hepatoprotective activity.

The air-dried powder $(1 \mathrm{~kg})$ of fresh mature leaves of $A$. indica were extracted by percolation at room temperature with 70\% ethanol. The extract was concentrated under reduced pressure (bath temp. $50{ }^{\circ} \mathrm{C}$ ) and dried in a vacuum desiccator. The residue was dissolved in distilled water and filtered. The filtrate was evaporated to dryness. The dried mass (yield = $50.2 \mathrm{~g}$ ) was suitably diluted with normal saline and used in experiments.

Male albino Wistar rats (100-150 g; 4-6 weeks old) were maintained under controlled conditions of light (12/24 h) and temperature $\left(23 \pm 1{ }^{\circ} \mathrm{C}\right)$. Food pellets and tap water were provided ad libitum. For experimental purposes animals were fasted overnight but were allowed free access to water.
Four groups of rats, six in each received the following treatment schedule.

Group I : Normal control (saline)

Group II : Paracetamol treated control (2 g/kg, p.o.).

Group III : Paracetamol (2 g/kg, p.o.) + A. indica leaf extract (500 mg/kg, p.o.)

Group IV : A. indica leaf extract (500 mg/kg, p.o.)

Leaf extract, paracetamol or saline was administered with the help of a feeding cannula. A fixed dose of the leaf extract (500 mg/kg, p.o.) dose was found to be the working dose from our previous experiments and was given once daily to Group III animals for 7 consecutive days and paracetamol $(2 \mathrm{~g} / \mathrm{kg}$, p.o.) was administered on $5^{\text {th }}$ day of the extract administration. After $48 \mathrm{~h}$ of paracetamol dosing the rats were sacrificed by cervical dislocation and liver removed immediately and transferred to ice cold container, homogenized and assayed for antioxidant enzymes (Glutathione peroxidase, glutathioneS-transferase, superoxide dismutase and catalase activity study using standard methods. ${ }^{[3]-[6]}$ The normal control group received no treatment whereas paracetamol treated control and $A$. indica leaf extract alone treated groups received normal saline and same procedure was followed as that of Gr III animals.

One-way ANOVA followed by Tukey-Kramer post test was used for comparing two groups. $\mathrm{P}<0.05$ was considered significant. Results are shown in Table 1.

Table 1 shows that the values of liver enzymes (GPx, GST , SOD, and CAT) were significantly lower in animals which received paracetamol alone than the normal control animals

\section{Table 1}

Effect of $A$. indica extract on antioxidant enzymes in liver of rats

\begin{tabular}{|c|c|c|c|c|}
\hline $\begin{array}{l}\text { Treatment } \\
(n=6)\end{array}$ & $\begin{array}{c}G P x \\
\left(U^{p} / g \text { protein) }\right.\end{array}$ & $\begin{array}{c}\text { GST } \\
\text { (Uq/mg protein) }\end{array}$ & $\begin{array}{c}\text { SOD } \\
\text { (Us/g protein) }\end{array}$ & $\begin{array}{c}\text { CAT } \\
\text { (Ut/g protein) }\end{array}$ \\
\hline Normal control (saline) & $19.6 \pm 1.4$ & $1291 \pm 68$ & $56.7 \pm 3.0$ & $68.8 \pm 4.1$ \\
\hline Paracetamol treated control & $11.2 \pm 1.0^{*}$ & $905 \pm 52^{*}$ & $40.2 \pm 2.7^{*}$ & $52.4 \pm 2.7^{*}$ \\
\hline Paracetamol $+A$. indica leaf extract & $17.3 \pm 1.5$ & $1182 \pm 57$ & $52.8 \pm 3.4$ & $66.7 \pm 2.4$ \\
\hline A. indica leaf extract & $18.8 \pm 1.2$ & $1421 \pm 94$ & $60.4 \pm 3.8$ & $71.3 \pm 3.7$ \\
\hline$F$ & 111.78 & 195.46 & 145.55 & 114.72 \\
\hline$d f$ & 3,20 & 3,20 & 3,20 & 3,20 \\
\hline$P$ & $<0.0001$ & $<0.0001$ & $<0.0001$ & $<0.0001$ \\
\hline
\end{tabular}

Values are mean \pm SEM; $n=6$ in each group. ${ }^{*}$ Significantly different when compared to saline and other treatment groups. GPx=Glutathione peroxidase $\left(\mathrm{U}^{\mathrm{P}}=\mu \mathrm{moles} \mathrm{GSH}\right.$ utilised $/ \mathrm{min})$. GST=Glutathione-S-transferase $\left(\mathrm{U}^{\mathrm{q}}=\mathrm{nmoles} \mathrm{CDNB}-\mathrm{GSH}\right.$ conjugate/min). SOD=Superoxide dismutase $\left(\mathrm{U}^{\mathrm{s}}=\mathrm{u} \mathrm{kat}\right) \mathrm{CAT}=\mathrm{Catalase}\left(\mathrm{U}^{\mathrm{t}}=\mathrm{nmoles}\right.$ of $\mathrm{H}_{2} \mathrm{O}_{2}$ decomposed/sec) 
(Group II Vs Group I). On the other hand, the group which received both $A$. indica leaf extract and paracetamol (Group III), the values of above enzymatic parameters were near normal compared to Group I animals and were significantly different from their paracetamol treated control group (Group III Vs Group II). But there was no significant difference between Group I and Group IV animals.

It is well documented that the hepatocellular enzymes (GPX, GST, SOD and CAT) serve as biomarkers of hepatocellular injury due to alcohol and drug toxicity.

Administration of $A$. indica leaf extract significantly enhanced the hepatic level of glutathione dependent enzymes and superoxide dismutase and catalase activity (Table 1) suggesting that the hepatoprotective effect of the extract on paracetamol induced hepatoxicity may be due to its antioxidant activity.

Chemical analysis of the $A$. indica leaf extract revealed that the extract contains following six compounds.

(i) Quercetin-3-0- $\beta$-D-glucoside

(ii) Myricetin -3-0-rutinoside

(iii) Quercetin-3-0-rutinoside

(iv) Kaempferol-3-O-rutinoside

(v) Kaempferol-3-0- $\beta$-D-glucoside

(vi) Quercetin-3-0- $\alpha$ L-rhamnoside

It is well documented that the compounds quercetin, rutin, Vitamins C and E are strong antioxidants. It is presumed that the quercetin and rutin compounds of Azadirachta indica leaf extract may be responsible for its hepatoprotective activity.

Thus it can be inferred that $A$. indica leaf extract may be a promising hepatoprotective agent and this activity may be due to its antioxidant activity. Further studies involving the extract and/or its chemical constituents are needed to pinpoint the findings. This report may serve as a prelude on this aspect.

\section{Acknowledgements}

Authors wish to acknowledge Prof. G. Podder, Professor and Head, Department of Chemistry, School of Tropical Medicine, Kolkata and Prof. Debasis Roy, Professor and Head, CSSC Unit, Indian Statistical Institute, Kolkata for their cooperation and help to carry out the work.

R. R. Chattopadhyay*, M. Bandyopadhyay** *Agricultural Sciences Unit, Indian Statistical Institute 203, Barrackpore Trunk Road, Kolkata - 700 108, India

** Department of Pharmacology, School of Tropical Medicine, Kolkata - 700 073, India E-mail: rabi@isical.ac.in

\section{References}

1. Meredith TJ, Vale JA, Proudfoot AT. Poisoning caused by analgesics. In: Oxford textbook of medicine. Weatherall DJ, Ledingham JGG, Warrell DA, editors. $3^{\text {rd }}$ ed. Oxford: 1996.

2. Chattopadhyay RR, Sarkar SK, Ganguly S, Basu TK, Mukherjee A. Hepatoprotective activity of Azadirachta indica leaves on paracetamol induced hepatic damage in rats. Indian J Exp Biol 1992;30:738-40.

3. Rotruck JT, Pope AL, Ganther HE, Swanson AB, Hateman DG, Hoekstra WG. Selenium: Biochemical role as a component of glutathione peroxidase. Science 1973;179:588-90.

4. Habig WH, Pabst MJ, Jokaby WB. Glutathione-S-transferase. The first enzymatic step in mercapturic acid formation. J Biol Chem 1974;249:7130-9.

5. Mishra HP, Fridovich I. The role of superoxide anion in the autooxidation of epinephrine and a simple assay for superoxide dismutase. J Biol Chem 1972;247:3170-5

6. Takahara S, Hamilton BH, Nell JV, Kobra TY, Ogura Y, Nishimura ET. Hypocatalasemia: A new genetic carrier state. J Clin Invest 1960;39:610-9.

\section{PHARMA CME - 2005}

Date $\quad$ : July $9^{\text {th }}-10^{\text {th }}, 2005$

Place : Rangaraya Medical College, Kakinada, Andhra Pradesh

Theme : Modern Trends in Pharmacotherapeutics

Workshop : Non-invasive Techniques in Clinical Pharmacology

For further information please contact:

\author{
Organizing Secretary, \\ Department of Pharmacology, \\ Rangaraya Medical College, \\ Kakinada. Andhra Pradesh. \\ Ph: - $0884-2344836$
}

E-Mail : rmcpharma_2005@hot mail.com 